\title{
Femur başı ve boynu rekonstrüksiyonu endikasyonları
}

\author{
Indications of femoral head and neck reconstruction
}

\author{
Önder Kalenderer, Ali Turgut
}

Tepecik Eğitim ve Araştırma Hastanesi Ortopedi ve Travmatoloji Kliniği, İzmir

\begin{abstract}
Femur başı ve boynu ile ilgili deformiteler, genellikle çocukluk çağında geçirilen Legg-Calvé-Perthes, femur başı epifiz kayması, gelişimsel kalça displazisi ve kalça septik artriti gibi hastalıkların sekelleri olarak karşımıza çıkar. Erişkin döneminde ise, femur başı avasküler nekrozu, femur başında deformite oluşması ile sonuçlanabilir.

Fizisleri kapanmış, kalça hareketleri tama yakın olan, asetabulum kıkırdak dejenerasyonu olmayan, ağrı yakınması fazla olan, femur baş-boyun oranı artmış ve eklem hareketini engelleyen lezyonu olan ve rehabilitasyona uyum kapasitesi yüksek olan hastalar, femur baş-boyun rekonstrüksiyonu için uygun olan hastalardır.
\end{abstract}

Anahtar sözcülkler: femur başı; epifiz; femur baş-boyun yeniden şekillendirmesi; Legg-Calvé-Perthes hastalığı
K alça eklemi, omuz eklemi gibi fizyolojik hareket açıklıkları oldukça geniş olan bir eklemdir. Kalça eklem hareketlerinin tam açıklıkta olması; oturma, yürüme, koşma, zıplama, çömelme, merdiven inip çıkma ve bacak bacak üstüne atma gibi gündelik yaşantımızda rutin olarak yapmakta olduğumuz işlevlerimiz için kaçınılmazdır. Femur başı, çapı 45-56 mm arasında değişebilen bir kürenin yaklaşık 2/3'ü kadar yuvarlıktadır ve hiyalin kıkırdak ile kaplıdır. Normalde femur boynu ve başı, aksiyel planda femur kondillerine göre $15-20^{\circ}$ öne dönüktür (anteversiyon), asetabulum ise $20-40^{\circ}$ kadar antevert konumdadır. Sağlıklı bireylerde femur baş/boyun oranı 1,5 kadardır. ${ }^{[1]}$ Normal sınırlarda kalça eklem hareket açıklığı olması için, yukarıda bahsedilen özelliklere ek olarak, sağıklı bir eklem kıkırdağı, sferik femur başı ve buna uyumlu asetabulum varlığı gereklidir.
Femoral head and neck deformities of the hip joint are usually seen as a sequale of diseases in childhood such as Legg-Calvé-Perthes, slipped capital femoral epiphysis, developmental dysplasia of the hip and septic arthritis. On the other hand, avascular necrosis of the femoral head can result in formation of deformity in adulthood.

The patients are eligible for the femoral head and neck reconstruction if; physis are closed, range of motion of hip movements are close to full, there is no or minimally cartilage degeneration of the acetabulum, hip joint is painful, femoral head-neck ratio is increased, there is a lesion which prevents motion and the patient has capacity to adapt him/herself to the rehabilitation programme.

Key words: femoral head; epiphysis; femoral head-neck reconstruction; Legg-Calvé-Perthes disease

- Illetişim adresi: Doç. Dr. Önder Kalenderer, Tepecik Eğitim ve Araştırma Hastanesi Ortopedi ve Travmatoloji Kliniği, İzmir Tel: 0532 - 2971067 e-posta: okalenderer@gmail.com

- Geliș tarihi: 23 Ocak 2015 Kabul tarihi: 23 Ocak 2015

Femur başının asetabulum içinde fizyolojik sınırlarda hareket etmesini engelleyen femoral taraf veya asetabular taraf değişiklikleri oluşursa, kalça hareket açıklığı azalır, eklem kıkırdağı zarar görür ve ağrı oluşur. Sonuçta, yaşam konforu olumsuz yönde etkilenir.

Femur başı ve boynu ile ilgili deformiteler, genellikle çocukluk çağında geçirilen Legg-Calvé-Perthes (LCP), femur başı epifiz kayması (FBEK) ve gelişimsel kalça displazisi, kalça septik artriti gibi hastalıkların sekelleri olarak karşımıza çıkar. Erişkin döneminde ise, femur başı avasküler nekrozu, femur başında deformite oluşması ile sonuçlanabilir. Femur başında gelişimsel veya kazanılmış olarak oluşan deformite, yerleşim yerine göre, kalça fleksiyon-adduksiyon ve iç rotasyonu ya da kalça ekstansiyon-abduksiyon ve diş rotasyonu hareketleri ile "femoro-asetabular sıkışmaya" neden olur. Proksimal femur metafizindeki deformite veya sferik 
olmayan femur başı, sonuçta ağrı, asetabular taraf eklem kıkırdağında hasar ve bunları takiben osteoartroz oluşturabilir. ${ }^{[2-7]}$

Femur başı kanlanmasının ayrıntılı olarak anlaşılması ve cerrahi tekniklerde son dönemde yaşanan gelişmeler sayesinde artık, kalça eklemi femur başı kanlanması korunarak çıkarılabilmekte ve hem femur başboynunun hareketler esnasında asetabulum ile ilişkisi tam olarak anlaşılmakta hem de düzeltici işlemler ile bu ilişki fizyolojik sınırlara çekilebilmektedir. Proksimal femur düzeltici girişimler, en sık LCP ve FBEK hastalıklarının sekellerine uygulanmaktadır.

LCP hastalığının tedavisi, hastalığın aşamalarına göre dört zaman dilimine ayırılabilir. Bu aşamalar; 1) çökme henüz yok, 2) çökme var ancak ossifikasyon olmamış, 3) çökme var ve ossifikasyon oluşmuş, 4) remodele olmuş ve dejeneratif değişiklikler oluşmuş olarak gruplandırılabilir. ${ }^{[8]}$ Henüz çökmemiş olan femur başı varlığında, amaç çökmenin engellenmesidir (bifosfonatlar, kapsanma tedavileri). Çökme oluşmuş, ancak ossifikasyon henüz mevcut değil ise, yine femur başının kapsanması ve kalça hareket açıklığının korunması hedeflenir (yumuşak doku girişimleri, arthro-diastazis, osteotomiler). Femur başında çökme oluşmuş ve hastalıklı bölge yeniden ossifiye olmuş ise, tedavide amaç femoro-asetabular sıkışmayı önlemek ve sabit fleksiyon veya adduksiyon deformitelerinin gelişmesini engellemektir (valgizasyon osteotomisi, femur başı yeniden şekillendirme). ${ }^{[9,10]}$ Remodele olmuş ve dejeneratif eklem değişiklikleri başlamış olan hastalarda ise, femur başı yeniden şekillendirme, pelvik osteotomiler, kalça artrodezi ve artroplastisigibi geniş yelpazede tedavi seçenekleri bulunmaktadır. Ancak takdir ederseniz ki hiçbir hekim LCP hastalığı ile takip ettiği bir hastanın erken yaşta kalça artrodezi, artroplastisi gibi tedavilere maruz kalmasını arzu etmez. İşte bu yüzden amaç, dejeneratif eklem hastalığının gelişmesine izin vermeden, kalçanın fonksiyonlarına tam veya tama yakın kavuşturulması olmalıdır. Paley ve arkadaşları, ${ }^{[8]}$ güvenli çıkık ve Ganz osteotomisi ile yeniden şekillendirme uygulanan hastaların sonuçlarının cesaret verici olduğunu bildirmektedirler. Yazarlar, aşağıda belirtilen maddelere sahip hastalar için bu girişimin iyi bir endikasyon olduğunu belirtmektedirler.

1. Femur başında şekil bozukluğu olması.

2. Fleksiyon ve ekstansiyon hareket açıklığının iyi olması.

3. Asetabular kıkırdaktaki dejenerasyonun sınırı olması.

4. Femur baş ve boynundaki dejenerasyonun, yapılacak rezeksiyon ile ortadan kaldırılabilmesi.

5. Eliptik veya eyer (saddle) şekilli femur başı.
Önceden yapılmış olan bir intertrokanterik osteotomi, femur başının asetabuluma redüksiyonunu olumsuz yönde etkileyebilecektir.

Genişlemiş femur başına bağlı olarak deforme bir asetabulum varlığında, baş yeniden şekillendirilerek küçültüldüğünde, kalça eklemi instabilitesi oluşabileceği akılda tutulmalıdır. ${ }^{[11]}$

FBEK hastalarında tedavi ile hedeflenen, avasküler nekroz gelişmemiş fonksiyonel bir kalça elde edilmesidir. Yapılan çalışmalarda, hafif düzeydeki kaymalarda bile femur proksimal metafizer kısmı, lateralde hörgüç oluşturmakta ve asetabular kıkırdak hasarları oluşabilmektedir. ${ }^{[12]}$ Akut kaymalarda en sık uygulanan tedavi in situ vidalamadır. ${ }^{[13]}$ Kronik FBEK hastalarında, epifizin diziliminin düzeltilmesi amacı ile, bir takım proksimal femoral osreotomiler tanımlanmıştır (Dunn, Southwick, Kramer). Bir deformite, en iyi kendisine yakın yerden düzeltilebilir; dolayısıyla, yapılan subkapital osteotomiler deformiteyi en iyi şekilde düzeltebilirler, ancak bu girişimlerden sonra yüksek oranlarda avasküler nekroz komplikasyonları oluşabilmektedir. Öte yandan, güvenli kalça çıkığı uygulaması ile birlikte bu tip osteotomilerde iyi sonuçlar da bildirilmiştir. ${ }^{[14]}$ FBEK olgularında asetabular deformitelerin LCP hastalarına göre daha nadir oluşması, femur başı-boynu rekonstrüksiyon prosedürü sonuçlarının daha başarılı olmasını sağlayabilir.

Femur baş boyun rekonstrüksiyonu uygulanmış olan LCP hastalığı sekeline sahip bir hasta ile ilgili grafiler Şekil 1'de gösterilmiştir.

Sonuç olarak, femur baş-boyun rekonsrüksiyonu için uygun olan hastalar;

- fizisleri kapanmış,

- kalça fleksiyon ve ekstansiyon hareketleri çok etkilenmemiş,

- asetabular taraf eklem kıkırdağında ileri dejenerasyon olmayan,

- gündelik yaşamlarında ağrı ve hareket kısıtlılığı yakınmaları bulunan,

- femur baş/boyun oranı artmış,

- femur başlarında eklem hareketi engelleyen lezyonları bulunan,

- gelişebilecek komplikasyonları anlayabilen ve

- ameliyat sonrası fizik tedavi ve rehabilitasyon için uyumlu olanlar şeklinde sıralanabilirler.

Dikkat edilmesi gereken ise, bu tür girişimlerin tecrübeli ellerde yapılması gerekliliğidir. 

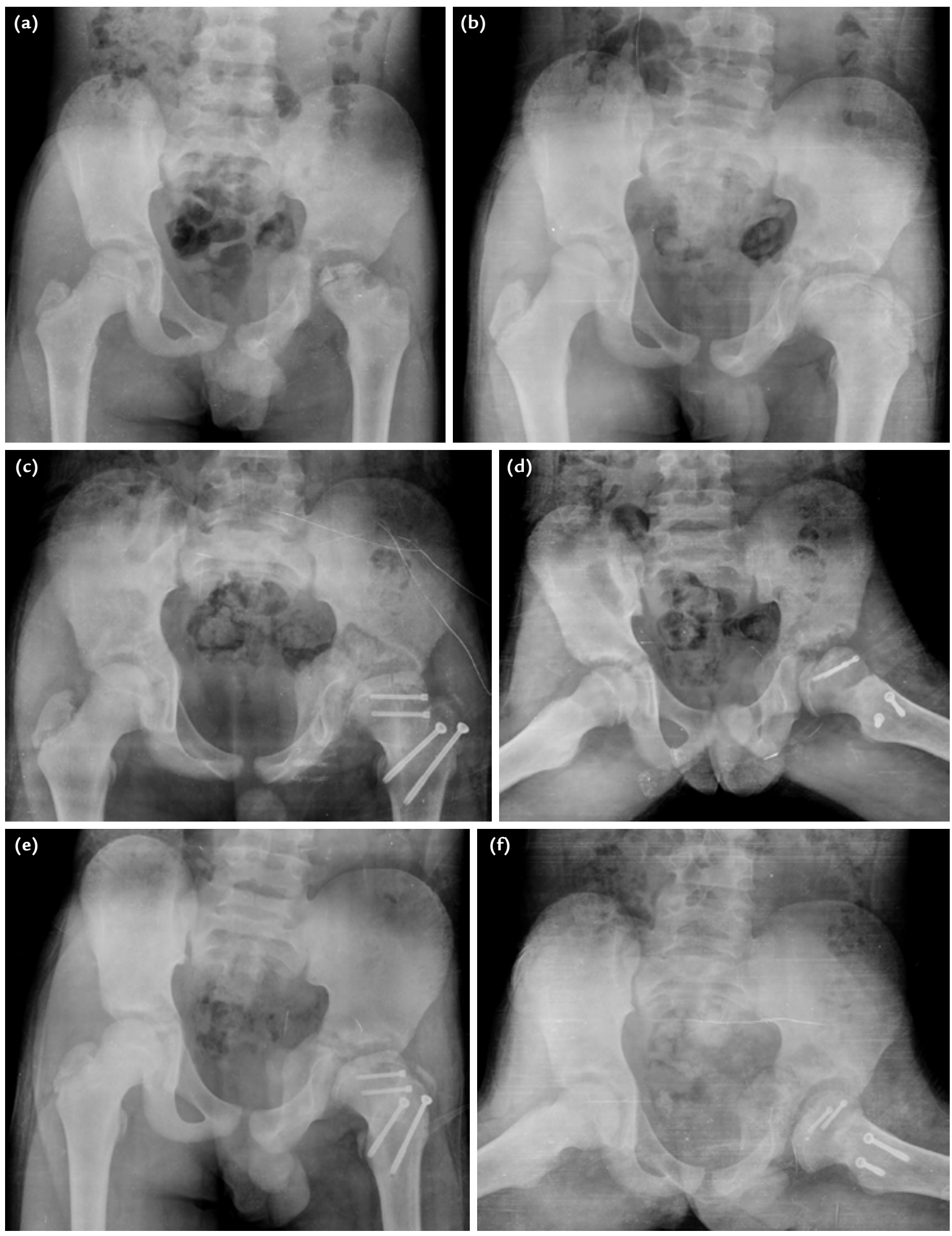

Şekil 1. a-f. Dokuz yaşında erkek çocukta sol kalça Legg-Calvé-Perthes hastalığı: Kötü prognostik faktörleri mevcut (a). Genişlemiş, deforme bir halde iyileşmiş (b). Femur baş-boyun yeniden şekillendirme uygulanmış (c, d). Ameliyat sonrası 14. ay (e, f). 


\section{KAYNAKLAR}

1. Jamali AA, Mak W, Wang P, Tai L, Meehan JP, Lamba R. What is normal femoral head/neck anatomy? An analysis of radial $C T$ reconstructions in adolescents. Clin Orthop Relat Res 2013;471(11):3581-7. CrossRef

2. Beck $M$, Kalhor $M$, Leunig $M$, Ganz R. Hip morphology influences the pattern of damage to the acetabular cartilage: femoroacetabular impingement as a cause of early osteoarthritis of the hip. J Bone Joint Surg $\mathrm{Br}$ 2005;87:1012-8.

3. Beck M, Leunig M, ParviziJ, Boutier V, Wyss D, Ganz R. Anterior femoroacetabular impingement: Part II. Midterm results of surgical treatment. Clin Orthop Relat Res 2004;(418):67-73.

4. Ganz R, Parvizi J, Beck M, Leunig M, Nötzli H, Siebenrock KA. Femoroacetabular impingement: a cause for osteoarthritis of the hip. Clin Orthop Relat Res 2003;(417):112-20.

5. Leunig $M$, Casillas MM, Hamlet $M$, Hersche $O$, Nötzli $H$, Slongo T, Ganz R. Slipped capital femoral epiphysis: early mechanical damage to the acetabular cartilage by a prominent femoral metaphysis. Acta Orthop Scand 2000;71(4):370-5.

6. Siebenrock KA, Wahab KH, Werlen S, Kalhor M, Leunig M, Ganz R. Abnormal extension of the femoral head epiphysis as a cause of cam impingement. Clin Orthop Relat Res 2004;(418):54-60.

7. Tannast M, Goricki D, Beck M, Murphy SB, Siebenrock KA. Hip damage occurs at the zone of femoroacetabular impingement. Clin Orthop Relat Res 2008;466(2):273-80. CrossRef
8. Paley D. The treatment of femoral head deformity and coxa magna by the Ganz femoral head reduction osteotomy. Orthop Clin North Am 2011;42(3):389-99. CrossRef

9. Ganz R, Huff TW, Leunig M. Extended retinacular soft tissue flap for intra-articular hip surgery: surgical technique, indications, and results of application. Instr Course Lect 2009;58:241-55.

10. Ganz R, Horowitz K, Leunig M. Algorithm for combined femoral and periacetabular osteotomies in complex hip deformities. Clin Orthop Relat Res 2010;468(12):3168-80. CrossRef

11. Wenger DR, Hosalkar HS. Principles of treating the sequelae of Perthes disease. Orthop Clin North Am 2011;42(3):36572. CrossRef

12. Leunig M, Fraitzl CR, Ganz R. Frühe Schädigung des azetabulären Knorpels bei der Epiphyseolysis capitis femoris. Therapeutische Konsequenzen [Early damage to the acetabular cartilage in slipped capital femoral epiphysis. Therapeutic consequences]. Orthopade 2002;31(9):894-9.

13. Günaydın B, Taşkıran MC, Turgut A, Kalenderer Ö. In situ pinning of stable type mild and moderately slipped femoral capital epiphysis with single screw fixation. SETB. Online First: 25 Aug, 2014. CrossRef

14. Leunig M, Slongo T, Kleinschmidt M, Ganz R. Subcapital correction osteotomy in slipped capital femoral epiphysis by means of surgical hip dislocation. Oper Orthop Traumatol 2007;19(4):389-410. 